\title{
Association of thymidylate synthase expression and clinical outcomes of gastric cancer patients treated with fluoropyrimidine-based chemotherapy: a meta-analysis
}

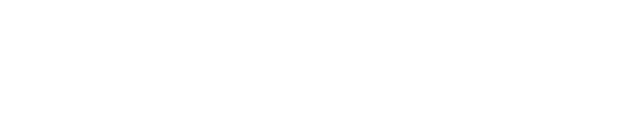

\section{Yunhe Gao* \\ Jianxin Cui* \\ Hongqing $\mathrm{Xi}^{*}$ \\ Aizhen Cai \\ Weisong Shen \\ Jiyang $\mathrm{Li}$ \\ Kecheng Zhang \\ Bo Wei \\ Lin Chen}

Department of General Surgery, Chinese People's Liberation Army General Hospital, Beijing, People's Republic of China

*These authors contributed equally to this work
Correspondence: Lin Chen

Department of General Surgery, Chinese People's Liberation Army General

Hospital, 28 Fuxing Road, Beijing I00853,

People's Republic of China

Tel +86 I06693 8I28

Email chenlinbj@sina.com
Purpose: Although several studies have suggested an association between thymidylate synthase (TS) expression and outcomes of gastric cancer (GC) patients treated with fluoropyrimidinebased chemotherapy (FUC), the predictive value of TS for response and survival in this setting is unclear. This meta-analysis aimed to estimate prognostic and predictive significance of TS more precisely.

Methods: We searched PubMed, Embase, Cochrane Library, and Web of Science databases for literature published up to June 2015. Primary outcomes included hazard ratios (HRs) for overall survival (OS), and event-free survival (EFS) and odds ratio (OR) for chemotherapy response. Fixed- or random-effects models were used to calculate pooled HR and OR according to heterogeneity.

Results: A total of 2,442 GC patients in 25 studies met our inclusion criteria. Response rates for FUC were significantly lower in patients with high TS expression than in those with low expression (OR: $0.43,95 \%$ confidence interval [CI]: 0.22-0.84, $P=0.013$ ). High TS expression was significantly correlated with unfavorable OS (HR: $1.62,95 \% \mathrm{CI}: 1.28-2.05, P<0.001)$ and EFS (HR: $1.54,95 \%$ CI: $1.22-1.93, P<0.001$ ) in advanced disease. However, TS expression was not significantly related to OS (HR: $1.06,95 \% \mathrm{CI}: 0.74-1.50, P=0.760)$ or EFS (HR: 1.16 , 95\% CI: $0.84-1.61, P=0.374)$ in the adjuvant setting.

Conclusion: Higher TS expression might predict drug resistance and adverse prognosis in patients with advanced GC treated with FUC.

Keywords: thymidylate synthase, gastric cancer, meta-analysis, fluoropyrimidine-based chemotherapy, clinical outcomes

\section{Introduction}

Gastric cancer (GC) is the third leading cause of cancer-related death worldwide, according to the World Health Organization's (WHO's) 2014 World Cancer Report. ${ }^{1}$ Although surgery remains the only potential curative treatment for GC, fluoropyrimidine (FU) and platinum chemotherapy have been shown to improve outcomes of GC patients. As a cornerstone of gastrointestinal cancer chemotherapy, single or combined chemotherapy with these two drugs is recommended for both localized and advanced GC patients. ${ }^{2}$ Moreover, newly developed FU-based chemotherapies (FUCs) including capecitabine and S- 1 have improved antitumor effects and reduced side effects. ${ }^{3}$ However, as drug resistance due to tumor heterogeneity is still a major obstacle to ideal clinical outcomes, ${ }^{4}$ more precise predictors of outcomes for patients who undergo FUC regimens are needed. 
Thymidylate synthase (TS) is the rate-limiting enzyme in the de novo synthesis of deoxythymidine monophosphate from deoxyuridine monophosphate, which uses 5,10-methylenetetrahydrofolate as a methyl donor. ${ }^{5}$ TS plays a critical role in one-carbon metabolism pathway, which is a centered pathway involved in folate metabolism and DNA synthesis. TS is an FU-binding target in its metabolism. FU may prevent TS from binding to its normal substrate, deoxyuridine monophosphate, thus inhibiting DNA synthesis. ${ }^{6}$ The role of TS expression as a predictor of sensitivity to FUs has been demonstrated in vitro; therefore, its intratumoral expression in vivo may play an important role in determining tumor sensitivity to FU. However, the precise association between TS status and FUC efficacy remains controversial. Yeh et $\mathrm{al}^{7}$ discovered that higher intratumoral TS status was significantly correlated with poorer survival in patients with GC, whereas Sasako et $\mathrm{al}^{8}$ found a reverse effect for TS expression in survival of GC patients from the ACTS-GC trial. In terms of meta-analysis, Hu et al's study found no association between TS expression and FUC response, which is inconsistent with the most up-to-date results. Because of the paradoxical results of different studies, we conducted this meta-analysis to determine the accurate relation between TS expression and clinical outcomes in GC patients receiving FUC. Our entire analysis was conducted in two parts based on treatment setting: the advanced setting was defined as patients with advanced GC who were receiving palliative chemotherapy and the adjuvant setting was defined as patients who had undergone radical resection for GC and were receiving adjuvant chemotherapy.

\section{Materials and methods}

\section{Search strategy}

The search was conducted by consulting the online database PubMed, Embase, Web of Science, and Cochrane Library for all relevant papers published before June 30, 2015. The search strategy was performed using the following terms: "thymidylate synthase" OR "TS" OR "TYMS" and "stomach neoplasms" OR "stomach cancer" OR "gastric cancer" OR "gastric tumor". Article language was limited to English. The references of all relevant articles were reviewed to identify additional related studies. Two reviewers (YG and JC) independently assessed the eligibility of the relevant studies, and disagreements were resolved by discussion or consultation with a third researcher.

\section{Selection criteria}

In this meta-analysis, studies that met the following criteria were selected as candidate articles: (1) inclusion of pathologically confirmed GC patients; (2) patients receiving FUC; (3) primary outcomes of overall survival (OS) or event-free survival (EFS) (disease-free survival [DFS], progression-free survival, or time to relapse or time to progression); (4) investigation of the relationship between intratumoral TS status and survival; (5) available data for calculation of hazard ratios (HRs) or odds ratios (ORs) with their corresponding 95\% confidence intervals (CIs). And the following exclusion criteria were used: (1) abstracts and reviews, (2) publications in non-English language, (3) insufficient data to extract or calculate the HRs or ORs, (4) repeated or overlapping publications, and (5) poor quality of research article (Newcastle-Ottawa Quality Assessment Scale [NOS] score $<5$, methodological score $<60)$.

\section{Data extraction}

The following items were extracted from the eligible studies: name of the first author, publication year, regions, disease stage, sample size, treatment setting, chemotherapy regimens, TS detection method, the cutoff point to categorize high and low TS expression, and number or percentage of patients with high TS expression in each study. The HRs for OS or EFS, ORs for chemotherapy response, and their $95 \%$ CIs were collected from the studies. If HRs or ORs were not directly reported, survival data would be extracted from the KaplanMeier curves using the methods illustrated by Parmar et a ${ }^{10}$ and Tierney et al. ${ }^{11}$

\section{Quality assessment and methodological assessment}

Two researchers (HX and KZ) independently reviewed all the retrieved studies and assessed the quality by using the NOS for cohort studies. ${ }^{12}$ This scale is an eight-item instrument that allows for assessment of patient population and selection, study comparability, and outcomes. We considered a study awarded five or more stars as a high-quality one.

Methodological assessment was also conducted by two investigators independently ( $\mathrm{HX}$ and KZ) according to European Lung Cancer Working Party quality scale for biological prognostic factors for lung cancer. ${ }^{13}$ The scale consists of four aspects of methodology: the scientific design, laboratory methodology, generalizability, and the analysis of the results. Each aspect had a maximal score of ten points and the total maximum theoretical score of 40 points. The final assessment was displayed as percentages of 40 points, with the higher values indicating a better methodological quality. And any article that scored $<60$ percentage points was excluded from the analysis. 


\section{Statistical analysis}

In this meta-analysis, the end points of OS, EFS, and response rate to chemotherapy were applied for pooled analysis. When interpreting the results, HR $>1$ indicated that patients with high TS expression had a low chance of survival compared with those with low TS expression; OR $<1$ indicated that low TS expression improves FUC response in GC patients. We evaluated the between-study heterogeneity by using the Cochran $Q$ and $I^{2}$ statistics. A significant heterogeneity was observed when $P<0.1$ or $I^{2}>50 \%$, and a random-effect model was employed. Otherwise, a fixed-effect model was employed. Meta-regression and subgroup analysis by region, chemotherapy regimen, sample size, detection method, and tumor node metastasis (TNM) stage proportion were applied for exploring the significant heterogeneity reasons. We also employed sensitivity analysis to evaluate stability of the results. Publication bias was evaluated using the Egger's and Begg's test. ${ }^{14}$ Two-sided $t$-test was employed in the comparison of quality scores in different groups. And all statistical significance was defined as $P<0.05$. Statistical analysis was performed by using the STATA 12.0 software (StatCorp, College Station, TX, USA) or SPSS 17.0 (SPSS Inc, Chicago, IL, USA).

\section{Ethical approval}

This article did not require ethical approval or patient consent as it does not contain any studies with human participants. All the analyses were based on previous published studies.

\section{Results \\ Eligible studies and characteristics}

Five hundred and eighty-one studies were retrieved from a search of the above-mentioned databases using strategies as described earlier. Two hundred and seventy-eight, 214, 89, and three studies were identified from PubMed, Embase, Web of Science, and Cochrane Library, respectively. After carefully reviewing the titles and abstracts, 193 duplicates were excluded, and 24 were excluded because they were not published in English. Next, 256 studies were excluded because they did not meet the eligible criteria for our analysis. In the remaining 108 articles, 34 were excluded due to their irrelevance to FUC. Moreover, eight reports were excluded because they assessed serous TS expression other than intratumoral TS, and five more were excluded due to the low quality of article. And 36 were removed due to the insufficient data provided by the authors to calculate the HRs or ORs. Specifically, the patient population from the studies of Kwon et al and Kim et al was selected from the same university receiving different chemotherapy regimens, ${ }^{15,16}$ thus, we regarded them as two independent studies. Finally, a total of 25 studies satisfying the inclusion criteria were enrolled in our meta-analysis (Figure 1).

\section{Quality assessment}

All the studies scored over 60 percentage points in terms of methodology and six points of NOS. Unsurprisingly, there was a significant difference between the 14 indirect and the eleven direct HR extraction studies in the methodology assessment $(t=2.465, P=0.022)$. Interestingly, ten out of 14 indirect extraction studies were from the advanced setting. Although statistical analysis did not demonstrate a significant difference from the disease setting scope $(t=1.315, P=0.202)$, we did observe a relatively high-quality trend in the adjuvant setting.

\section{Study characteristics}

The general characteristics of 25 included studies are presented in Table 1. Among these studies, 13 were classified as the adjuvant setting and 12 as the advanced setting. In the adjuvant setting, ten studies evaluated patients from East Asia (two from People's Republic of China, one from Taiwan, five from Korea, and three from Japan) and two from Europe (Spain and Switzerland/Italy). The 13 studies comprised 1,824 patients for pooling analysis (median 89, range 39-463). A variety of chemotherapy regimens were applied: combined treatment with at least one kind of FU drugs was applied in ten studies, S-1 monotherapy was applied in two studies, and 5-FU and radiation combined therapy was applied in one study.

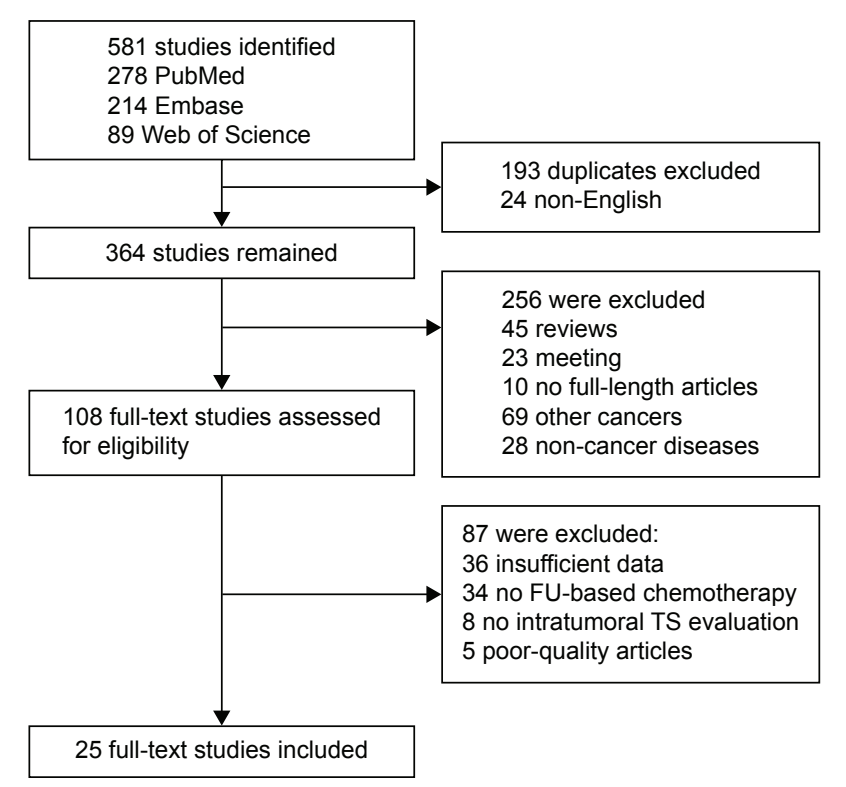

Figure I Flow chart of selection process to enroll eligible studies. Abbreviations: FU, fluorouracil; TS, thymidylate synthase. 


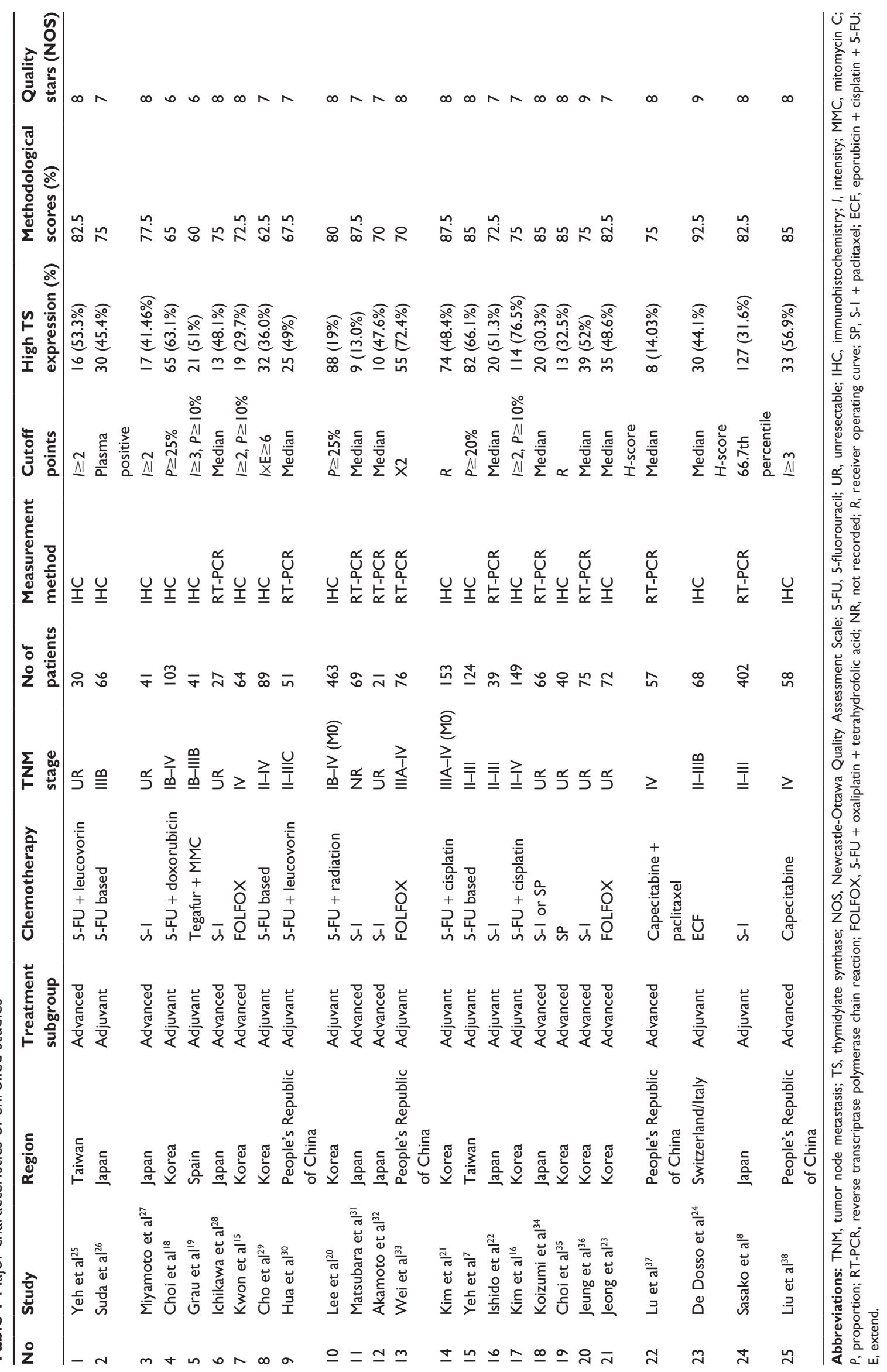


In the advanced setting, all the 12 studies enrolled patients from East Asian countries (two from People's Republic of China, one from Taiwan, four from Korea, and five from Japan). The 12 studies comprised 620 patients for pooling analysis (median 58, range 21-75). Among these studies, combined chemotherapy (FU and cisplatin or oxaliplatin or paclitaxel or leucovorin) was applied in five studies, monotherapy was applied in six studies (S-1 or capecitabine), and mixed therapy (FU-based monotherapy and combined chemotherapy coexisted) was applied in one study. In terms of chemotherapy response, ten studies were included for pooling analysis. All of these studies were enrolled from the advanced setting except that of Yeh et al, which was retrieved from the adjuvant setting and defined responders as patients of DFS $>2$ years after receiving the FU-based adjuvant chemotherapy. ${ }^{7}$ Four studies applied Response Evaluation Criteria in Solid Tumors to assess the chemotherapy response, five applied the Union for International Cancer Control guidelines $^{2}$ or WHO criteria, ${ }^{17}$ and one defined their own standard. ${ }^{7}$ Median follow-up time was only explicitly reported in eight of 25 studies (median 66.6 months, range 12-118 months). ${ }^{16,18-24}$ And all of the eight studies stated the minimum and maximum follow-up (range 2.0-189 months).

\section{Meta-analysis results}

Association between TS expression and clinicopathological features

The association between TS overexpression and major clinicopathological features was assessed. As shown in Table 2, TS overexpression had a significant association with Lauren classification (diffuse vs intestinal - OR: 0.48, 95\% CI: 0.26-0.88, $P=0.017$ ). And no statistical association was observed between TS expression and sex (male vs female - OR: $1.16,95 \%$ CI: $0.88-1.53, P=0.294$ ), as well as lymph node metastasis or TNM stage, but we did notice an increased trend of TS expression in patients with higher grade and more metastatic lymph nodes, which might have a clinical influence. (TNM stage I + II vs III + IV - OR: 0.48, 95\% CI: 0.23-1.01, $P=0.054$; lymph node metastasis negative vs positive - OR: $0.58,95 \%$ CI: 0.31-1.09, $P=0.09$ ).

The main results of the meta-analysis for survival and chemotherapy response are presented in Table 3.

\section{TS expression and response rate for chemotherapy}

Finally, ten studies were eligible for the analysis of OR (Figure 2). All the studies were selected from the advanced setting, except that of Yeh et al. ${ }^{7}$ The pooled OR for chemotherapy response in GC patients with higher TS expression receiving FUC was 0.43 (95\% CI: $0.22-0.84, P=0.013$ ) compared with those with lower TS expression, with moderate heterogeneity $\left(I^{2}=64.5 \%, P=0.003\right)$. Sensitivity analysis demonstrated that omission of any single study would not alter the impact of the final result. And subgroup analysis stratified by study region has minimized the intergroup heterogeneity (Figure 3), which displayed a more significant link between TS status and FUC response in People's Republic of China (OR: $0.22,95 \% \mathrm{CI}: 0.13-0.38, P<0.001$ ) and Japan (OR: $0.43,95 \%$ CI: $0.20-0.91, P=0.027$ ) than Korea (OR: $1.28,95 \%$ CI: $0.65-2.51, P=0.468$ ). On the other hand, subgroup analysis according to other factors did not change the between-study heterogeneity. These findings indicate statistically significant favorable clinical outcomes for GC patients with low TS expression after FUC.

\section{The effect of TS expression on OS and EFS in adjuvant setting}

Twelve studies provided available data for the analysis of OS, as well as ten for the analysis of EFS (Figures 4 and 5). The pooled HR for OS in adjuvant setting was $1.06(95 \%$ CI: $0.74-1.50)$ with significant heterogeneity $\left(I^{2}=76.2 \%\right.$, $P<0.001)$. And the pooled HR for EFS in adjuvant setting was 1.16 (95\% CI: 0.84-1.61) with evidence of heterogeneity $\left(I^{2}=69.1 \%, P=0.001\right)$. Judging from the considerable heterogeneity, a random-effect model was applied in this analysis. We performed a subgroup analysis and meta-regression analysis to explore the heterogeneity source stratified by study region, race, chemotherapy regimen, detection method,

Table 2 Meta-analysis of the association between TS expression and clinicopathological features of gastric cancer

\begin{tabular}{|c|c|c|c|c|c|c|c|}
\hline \multirow[t]{2}{*}{ Stratification } & \multirow{2}{*}{$\begin{array}{l}\text { No of } \\
\text { studies }\end{array}$} & \multirow{2}{*}{$\begin{array}{l}\text { No of } \\
\text { patients }\end{array}$} & \multirow{2}{*}{$\begin{array}{l}\text { Pooled } \\
\text { OR }\end{array}$} & \multirow{2}{*}{$\begin{array}{l}95 \% \mathrm{Cl} \text { of } \\
\text { pooled OR }\end{array}$} & \multirow[t]{2}{*}{$P$-value } & \multicolumn{2}{|c|}{ Heterogeneity } \\
\hline & & & & & & $P^{2}(\%)$ & $P$-value \\
\hline Sex & 8 & $44 I$ & 1.16 & $0.88-1.53$ & 0.294 & 9.6 & 0.356 \\
\hline TNM stage & 2 & 163 & 0.48 & $0.23-1.01$ & 0.054 & 0 & 0.496 \\
\hline Lauren classification & 4 & 208 & 0.48 & $0.26-0.88$ & 0.017 & 0 & 0.859 \\
\hline Lymph node & 3 & 273 & 0.58 & $0.31-1.09$ & 0.09 & 55.8 & 0.104 \\
\hline
\end{tabular}

Abbreviations: TS, thymidylate synthase; OR, odds ratio; $\mathrm{Cl}$, confidence interval; TNM, tumor node metastasis. 
Table 3 Results of survival and response to chemotherapy in individual study

\begin{tabular}{|c|c|c|c|c|c|c|c|c|c|}
\hline \multirow[t]{2}{*}{$\overline{\text { Study }}$} & \multicolumn{3}{|c|}{ Overall survival } & \multicolumn{3}{|c|}{ Event-free survival } & \multicolumn{3}{|c|}{ OR for response } \\
\hline & HR & $95 \% \mathrm{Cl}$ & $P$-value & HR & $95 \% \mathrm{Cl}$ & $P$-value & OR & $95 \% \mathrm{Cl}$ & $P$-value \\
\hline Yeh et $\mathrm{al}^{25}$ & $2.60(\mathrm{~K})$ & $1.27-5.33$ & 0.009 & & & & 0.01 & $0.00-0.14$ & 0.000 \\
\hline Suda et $\mathrm{a}^{26}$ & $2.14(\mathrm{M})$ & $1.07-4.28$ & 0.031 & & & & & & \\
\hline Miyamoto et $\mathrm{al}^{27}$ & $1.16(\mathrm{~K})$ & $0.59-2.29$ & a & & & & $1.05 \mid$ & $0.302-3.65 I$ & 0.938 \\
\hline Choi et al ${ }^{18}$ & $1.46(\mathrm{~K})$ & $0.8 \mathrm{I}-2.62$ & 0.604 & $1.17(\mathrm{~K})$ & $0.65-2.12$ & 0.802 & & & \\
\hline Grau et al ${ }^{19}$ & & & & $2.01(K)$ & $0.27-14.87$ & a & & & \\
\hline Ichikawa et $\mathrm{al}^{28}$ & $4.48(\mathrm{~F})$ & 2. $10-9.52$ & $<0.0001$ & & & & 0.08 & $0.01-0.83$ & 0.034 \\
\hline Kwon et $\mathrm{al}^{15}$ & $1.23(\mathrm{~F})$ & $0.72-2.09$ & 0.4578 & $\mathrm{I} .2 \mathrm{I}(\mathrm{F})$ & $0.7 \mathrm{I}-2.07$ & $0.48 \mathrm{I}$ & 0.88 & $0.29-2.65$ & 0.813 \\
\hline Cho et $\mathrm{al}^{29}$ & $0.55(\mathrm{~K})$ & $0.31-0.97$ & 0.0392 & & & & & & \\
\hline Hua et $\mathrm{al}^{30}$ & $2.52(\mathrm{M})$ & $1.30-4.862$ & 0.006 & $1.95(\mathrm{~F})$ & $1.13-3.38$ & 0.017 & & & \\
\hline Lee et $\mathrm{al}^{20}$ & $0.866(M)$ & $0.593-1.266$ & 0.459 & I.II (F) & $0.88-|.4|$ & $0.36 \mathrm{I}$ & & & \\
\hline Matsubara et $\mathrm{al}^{31}$ & & & & $2.11(U)$ & $0.97-4.55$ & 0.131 & 0.35 & $0.11-1.10$ & $0.07 \mid$ \\
\hline Akamoto et $\mathrm{al}^{32}$ & $2.27(\mathrm{~K})$ & $0.92-5.59$ & 0.074 & & & & & & \\
\hline Wei et $\mathrm{al}^{33}$ & $0.52(F)$ & $0.3 \mathrm{I}-0.85$ & 0.01 & & & & & & \\
\hline Kim et $\mathrm{al}^{21}$ & $0.725(U)$ & $0.467-1.127$ & 0.153 & $0.927(U)$ & $0.620-1.387$ & 0.712 & & & \\
\hline Yeh et $\mathrm{al}^{7}$ & $2.2(\mathrm{M})$ & $1.29-3.83$ & 0.004 & $2.06(\mathrm{M})$ & I.18-3.58 & 0.011 & 0.27 & $0.12-0.60$ & 0.001 \\
\hline Ishido et $\mathrm{a}^{22}$ & $5.38 \mathrm{I}(\mathrm{U})$ & I.159-24.985 & 0.032 & $6.128(U)$ & $1.31-28.63$ & 0.021 & & & \\
\hline Kim et $\mathrm{al}^{16}$ & $0.76(F)$ & $0.44-1.30$ & 0.319 & $0.67(\mathrm{~F})$ & $0.39-1.15$ & 0.145 & & & \\
\hline Koizumi et al ${ }^{34}$ & $1.70(U)$ & $0.96-3.01$ & 0.0694 & & & & & & \\
\hline Choi et a $\left.\right|^{35}$ & $1.17(\mathrm{~K})$ & $0.60-2.26$ & 0.647 & $\mathrm{I} .40(\mathrm{~K})$ & $0.72-2.70$ & 0.736 & 1.26 & $0.33-4.73$ & 0.736 \\
\hline Jeung et $\mathrm{a}^{36}$ & $1.38(\mathrm{~K})$ & $0.87-2.19$ & 0.175 & $\mathrm{I} .56(\mathrm{~K})$ & $0.98-2.47$ & 0.060 & 1.95 & $0.63-6.03$ & 0.250 \\
\hline Jeong et $\mathrm{a}^{23}$ & $1.08(F)$ & $0.65-1.79$ & 0.767 & & & & & & \\
\hline Lu et $\mathrm{a}^{37}$ & $1.35(F)$ & $0.80-2.27$ & 0.257 & I.I4 (F) & $0.68-1.92$ & 0.617 & 0.325 & $0.108-0.975$ & 0.045 \\
\hline De Dosso et $\mathrm{al}^{24}$ & $1.769(U)$ & $0.403-7.768$ & 0.450 & $\mathrm{I} .489(\mathrm{U})$ & $0.283-7.823$ & 0.638 & & & \\
\hline Sasako et $\mathrm{a}^{8}$ & $0.521(U)$ & $0.319-0.820$ & 0.008 & $0.530(U)$ & $0.344-0.816$ & 0.003 & & & \\
\hline Liu et $\mathrm{a}^{38}$ & $2.32(\mathrm{~F})$ & $1.36-3.96$ & 0.002 & $2.45(\mathrm{~F})$ & $1.44-4.18$ & 0.001 & 0.258 & $0.082-0.815$ & 0.021 \\
\hline
\end{tabular}

Notes: K: extracted and calculated from the Kaplan-Meier curves in the studies; F: calculated by the formula provided by Parmar et al ${ }^{10}$; U: univariate analysis; and

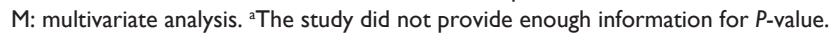

Abbreviations: $\mathrm{HR}$, hazard ratio; $\mathrm{Cl}$, confidence interval; $\mathrm{OR}$, odds ratio.

\begin{tabular}{|c|c|c|}
\hline Study ID & OR $(95 \% \mathrm{Cl})$ & $\%$ weight \\
\hline Yeh et $\mathrm{al}^{25}$ & $0.01(0.00,0.14)$ & 4.89 \\
\hline Miyamoto et $\mathrm{al}^{27}$ & $1.05(0.30,3.65)$ & 10.44 \\
\hline Ichikawa et al ${ }^{28}$ & $0.08(0.01,0.83)$ & 5.55 \\
\hline Kwon et al ${ }^{15}$ & $0.88(0.29,2.65)$ & 11.31 \\
\hline Matsubara et al $\left.\right|^{31}$ & $0.35(0.11,1.10)$ & 11.03 \\
\hline Yeh et $\mathrm{al}^{7}$ & $0.27(0.12,0.60)$ & 13.31 \\
\hline Choi et $\mathrm{al}^{35}$ & $1.26(0.33,4.73)$ & 9.95 \\
\hline Jeung et $\mathrm{al}^{36}$ & $1.95(0.63,6.08)$ & 11.12 \\
\hline Lu et $\mathrm{al}^{37}$ & $0.32(0.11,0.98)$ & 11.36 \\
\hline Liu et $a^{38}$ & $0.26(0.08,0.81)$ & 11.05 \\
\hline Overall $\left(I^{2}=64.5 \%, P=0.003\right)$ & $0.43(0.22,0.84)$ & 100 \\
\hline
\end{tabular}

Figure 2 Forest plot of the OR for chemotherapy response to FU-based regimen on TS status.

Note: Weights are from random-effects analysis.

Abbreviations: OR, odds ratio; $\mathrm{FU}$, fluorouracil; TS, thymidylate synthase; $\mathrm{Cl}$, confidence interval. 


\begin{tabular}{|c|c|c|}
\hline Study ID & OR $(95 \% \mathrm{CI})$ & $\%$ weight \\
\hline \multicolumn{3}{|l|}{ People's Republic of China } \\
\hline Yeh et $\mathrm{al}^{25}$ & $0.01(0.00,0.14)$ & 4.89 \\
\hline Yeh et $\mathrm{al}^{7}$ & $0.27(0.12,0.60)$ & 13.31 \\
\hline Lu et $\mathrm{al}^{37}$ & $0.32(0.11,0.98)$ & 11.36 \\
\hline Liu et $\mathrm{al}^{38}$ & $0.26(0.08,0.81)$ & 11.05 \\
\hline Subtotal $\left(I^{2}=51.7 \%, P=0.102\right)$ & $0.21(0.09,0.49)$ & 40.61 \\
\hline \multicolumn{3}{|l|}{ Japan } \\
\hline Miyamoto et $\mathrm{al}^{27}$ & $1.05(0.30,3.65)$ & 10.44 \\
\hline Ichikawa et al ${ }^{28}$ & $0.08(0.01,0.83)$ & 5.55 \\
\hline Matsubara et $a^{31}$ & $0.35(0.11,1.10)$ & 11.03 \\
\hline Subtotal $\left(I^{2}=51.0 \%, P=0.130\right)$ & $0.40(0.12,1.35)$ & 27.01 \\
\hline \multicolumn{3}{|l|}{ Korea } \\
\hline Kwon et al ${ }^{15}$ & $0.88(0.29,2.65)$ & 11.31 \\
\hline Choi et al ${ }^{35}$ & $1.26(0.33,4.73)$ & 9.95 \\
\hline Jeung et $a^{36}$ & $1.95(0.63,6.08)$ & 11.12 \\
\hline Subtotal $\left(I^{2}=0.0 \%, P=0.612\right)$ & $1.28(0.65,2.53)$ & 32.38 \\
\hline Overall $\left(I^{2}=64.5 \%, P=0.003\right)$ & $0.43(0.22,0.84)$ & 100 \\
\hline
\end{tabular}

Figure 3 Forest plot of the subgroup analysis by different regions of studies.

Note: Weights are from random-effects analysis.

Abbreviations: $\mathrm{OR}$, odds ratio; $\mathrm{Cl}$, confidence interval.

\begin{tabular}{|c|c|c|}
\hline Study ID & $\mathrm{HR}(95 \% \mathrm{Cl})$ & $\%$ weight \\
\hline Suda et $a^{26}$ & $2.14(1.07,4.28)$ & 8.06 \\
\hline Choi et al ${ }^{17}$ & $1.46(0.81,2.62)$ & 8.86 \\
\hline Cho et $\mathrm{al}^{29}$ & $0.55(0.31,0.97)$ & 8.98 \\
\hline Hua et $\mathrm{al}^{30}$ & $2.17(1.20,3.93)$ & 8.81 \\
\hline Lee et $\mathrm{a}^{20}$ & $0.87(0.59,1.27)$ & 10.37 \\
\hline Wei et $\mathrm{al}^{33}$ & $0.52(0.31,0.85)$ & 9.48 \\
\hline Kim et $\mathrm{al}^{21}$ & $0.73(0.47,1.13)$ & 9.95 \\
\hline Yeh et $\mathrm{al}^{7}$ & $2.20(1.29,3.83)$ & 9.18 \\
\hline Ishido et $\mathrm{al}^{22}$ & $5.38(1.16,24.99)$ & 3.60 \\
\hline Kim et $\mathrm{al}^{16}$ & $0.76(0.44,1.30)$ & 9.20 \\
\hline De Dosso et $\mathrm{al}^{24}$ & $1.77(0.40,7.77)$ & 3.79 \\
\hline Sasako et $\mathrm{al}^{8}$ & $0.52(0.32,0.82)$ & 9.72 \\
\hline Overall $\left(I^{2}=76.6 \%, P=0.000\right)$ & $1.07(0.75,1.52)$ & 100 \\
\hline
\end{tabular}

Figure 4 Forest plot of the HRs for OS in adjuvant setting on the TS status.

Note: Weights are from random-effects analysis.

Abbreviations: HRs, hazard ratios; OS, overall survival; TS, thymidylate synthase; $\mathrm{Cl}$, confidence interval. 


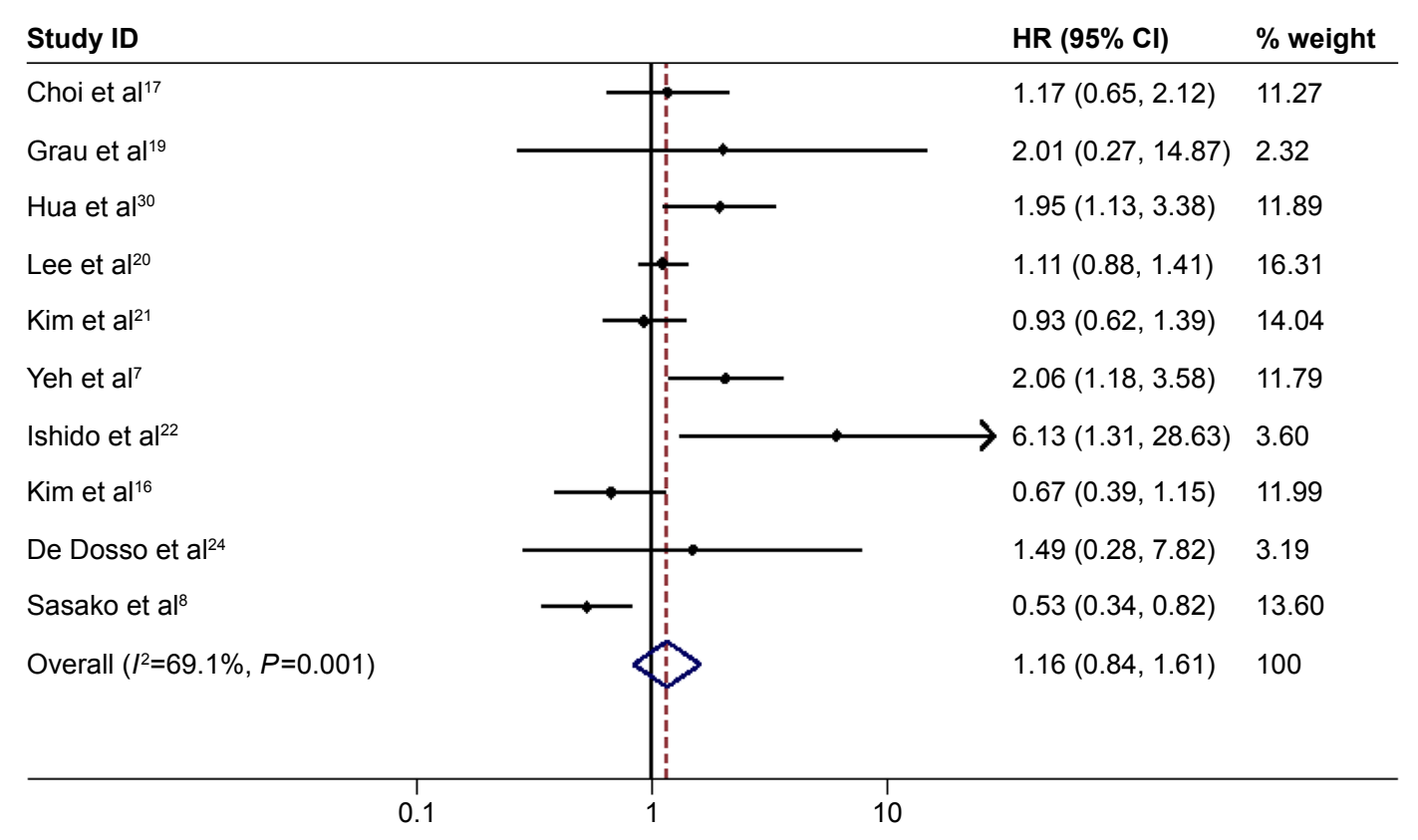

Figure 5 Forest plot of the HRs for EFS in adjuvant setting on the TS status.

Note: Weights are from random-effects analysis.

Abbreviations: HRs, hazard ratios; EFS, event-free survival; TS, thymidylate synthase; $\mathrm{Cl}$, confidence interval.

sample size, and TNM stages (Table 4). It turns out that neither meta-regression analysis nor subgroup analysis of the six factors had reduced the significant between-group heterogeneity. However, a decreased heterogeneity was observed in the region subgroup of Korea $\left(I^{2}=33.9, P=0.196\right)$ while significant heterogeneity still existed in other regions. Therefore, region could only account for part of the heterogeneity source. It may indicate that in the adjuvant setting, other unrecorded important

Table 4 Meta-regression and subgroup analysis of studies in the adjuvant setting reporting the association of TS status and overall survival

\begin{tabular}{|c|c|c|c|c|c|c|c|}
\hline \multirow[t]{2}{*}{ Study subgroup } & \multirow{2}{*}{$\begin{array}{l}\text { No of } \\
\text { studies }\end{array}$} & \multirow{2}{*}{$\begin{array}{l}\text { No of } \\
\text { patients }\end{array}$} & \multirow{2}{*}{$\begin{array}{l}\text { Pooled } \\
\text { HR }\end{array}$} & \multirow{2}{*}{$\begin{array}{l}95 \% \mathrm{Cl} \text { of } \\
\text { pooled HR }\end{array}$} & \multirow{2}{*}{$\frac{\text { Meta-regression }}{P \text {-value }}$} & \multicolumn{2}{|c|}{ Heterogeneity } \\
\hline & & & & & & $I^{2}(\%)$ & $P$-value \\
\hline Total & $12^{\mathrm{a}}$ & $\mathrm{I}, 783$ & 1.04 & $0.76-1.4 \mid$ & & 76.0 & 0.000 \\
\hline Region & & & & & $0.44 I$ & & \\
\hline People's Republic of China & 3 & 251 & 1.34 & $0.5 \mathrm{I}-3.56$ & & 89.5 & 0.000 \\
\hline Japan & 3 & 507 & 1.58 & $0.43-5.75$ & & 87.8 & 0.000 \\
\hline Korea & 5 & 957 & 0.82 & $0.62-1.07$ & & 33.9 & 0.196 \\
\hline Europe & I & 68 & 1.77 & $0.40-7.77$ & & NA & NA \\
\hline Race & & & & & 0.620 & & \\
\hline Mongolian & II & I,7।5 & 1.05 & $0.73-1.50$ & & 78.0 & 0.000 \\
\hline Caucasian & I & 68 & 1.07 & $0.40-7.77$ & & NA & NA \\
\hline Detection method & & & & & 0.899 & & \\
\hline $\mathrm{IHC}$ & 8 & 1,215 & 1.08 & $0.75-1.56$ & & 69.1 & 0.002 \\
\hline RT-PCR & 4 & 568 & 1.12 & $0.46-2.69$ & & 86.8 & 0.000 \\
\hline Chemotherapy regimen & & & & & 0.944 & & \\
\hline Monotherapy & 2 & 441 & 1.49 & $0.15-14.48$ & & 87.7 & 0.004 \\
\hline Combined & 10 & $\mathrm{I}, 342$ & 1.08 & $0.76-1.54$ & & 74.8 & 0.000 \\
\hline Sample size & & & & & 0.480 & & \\
\hline$<100$ & 6 & 389 & 1.34 & $0.66-2.71$ & & 81.5 & 0.000 \\
\hline$\geq 100$ & 6 & I,394 & 0.94 & $0.64-1.40$ & & 74.3 & 0.002 \\
\hline TNM stage proportion & & & & & 0.506 & & \\
\hline III, IV/I, II < $2^{\mathrm{b}}$ & $5^{c}$ & I, 185 & 0.86 & $0.59-1.24$ & & 52.6 & 0.077 \\
\hline III, IV/I, II $\geq 2$ & 6 & 598 & 1.14 & $0.62-2.10$ & & 83.2 & 0.000 \\
\hline
\end{tabular}

Notes: a Grau et al's ${ }^{19}$ study provided the results of EFS instead of OS. ${ }^{\mathrm{b}}$ The median ratio of III + IV/I + II in the eleven studies was 2.22 . 'Hua et al's ${ }^{30}$ study did not provide detailed data of TNM stage.

Abbreviations: TS, thymidylate synthase; HR, hazard ratio; $\mathrm{Cl}$, confidence interval; IHC, immunohistochemistry; RT-PCR, reverse transcriptase polymerase chain reaction; TNM, tumor node metastasis; NA, not available. 


\begin{tabular}{|c|c|c|}
\hline Study ID & $\mathrm{HR}(95 \% \mathrm{Cl})$ & $\%$ weight \\
\hline Yeh et $\mathrm{al}^{25}$ & $2.60(1.27,5.33)$ & 7.33 \\
\hline Miyamoto et $\mathrm{al}^{27}$ & $1.16(0.59,2.29)$ & 7.89 \\
\hline Ichikawa et $\mathrm{al}^{28}$ & $4.48(2.10,9.52)$ & 6.82 \\
\hline Kwon et al ${ }^{15}$ & $1.23(0.72,2.09)$ & 10.49 \\
\hline Akamoto et al ${ }^{32}$ & $2.27(0.92,5.59)$ & 5.26 \\
\hline Koizumi et al ${ }^{34}$ & $1.70(0.96,3.01)$ & 9.72 \\
\hline Choi et $\mathrm{al}^{35}$ & $1.17(0.60,2.26)$ & 8.12 \\
\hline Jeung et $a^{36}$ & $1.38(0.87,2.19)$ & 12.10 \\
\hline Jeong et $\mathrm{al}^{23}$ & $1.08(0.65,1.79)$ & 11.06 \\
\hline Lu et $\mathrm{al}^{37}$ & $1.35(0.80,2.27)$ & 10.74 \\
\hline Liu et $\mathrm{al}^{38}$ & $2.32(1.36,3.96)$ & 10.46 \\
\hline Overall $\left(I^{2}=41.5 \%, P=0.072\right)$ & $1.62(1.28,2.05)$ & 100 \\
\hline
\end{tabular}

Figure 6 Forest plot of the HRs for OS in advanced setting on the TS status.

Note: Weights are from random-effects analysis.

Abbreviations: $\mathrm{HR}$, hazard ratio; OS, overall survival; TS, thymidylate synthase; $\mathrm{Cl}$, confidence interval.

factors would alter the prognostic impact of TS expression on GC patients receiving adjuvant FUC, such as peri-operation treatment and surgical procedure. All these results suggested that there was no statistically significant association between TS status and survival of GC patients in the adjuvant setting.

\section{The effect of TS expression on OS and EFS in} advanced setting

Eleven studies provided sufficient data for the analysis of OS and six studies for the analysis of EFS (Figures 6 and 7).
The pooled HR for OS in the advanced disease studies was 1.62 (95\% CI: 1.28-2.05) with moderate heterogeneity $\left(I^{2}=41.5 \%, P=0.072\right)$, suggesting that patients with higher TS expression level were significantly associated with shorter survival time. Similarly, the pooled HR from six advanced studies for EFS was 1.54 (95\% CI: 1.22-1.93). And heterogeneity was not detected in the above setting $\left(I^{2}=11.1 \%\right.$, $P=0.344)$. All these results indicated that high TS expression might be an unfavorable prognostic predictor in advanced GC patients treated with FUC.

\begin{tabular}{|c|c|c|}
\hline Study ID & HR $(95 \% \mathrm{CI})$ & $\%$ weight \\
\hline Kwon et al ${ }^{15}$ & $1.21(0.71,2.07)$ & 18.24 \\
\hline Matsubara et $\mathrm{al}^{31}$ & $2.11(0.87,4.55)$ & 8.22 \\
\hline Choi et al ${ }^{35}$ & $1.40(0.72,2.70)$ & 12.48 \\
\hline Jeung et $\mathrm{al}^{36}$ & $1.56(0.98,2.47)$ & 23.46 \\
\hline Lu et $\mathrm{al}^{37}$ & $1.14(0.68,1.92)$ & 19.23 \\
\hline Liu et $\mathrm{al}^{38}$ & $2.45(1.44,4.18)$ & 18.37 \\
\hline Overall $\left(I^{2}=11.1 \%, P=0.344\right)$ & $1.54(1.21,1.97)$ & 100 \\
\hline
\end{tabular}

Figure 7 Forest plot of the HRs for EFS in advanced setting on the TS status.

Note: Weights are from random-effects analysis.

Abbreviations: HR, hazard ratio; EFS, event-free survival; TS, thymidylate synthase; $\mathrm{CI}$, confidence interval. 


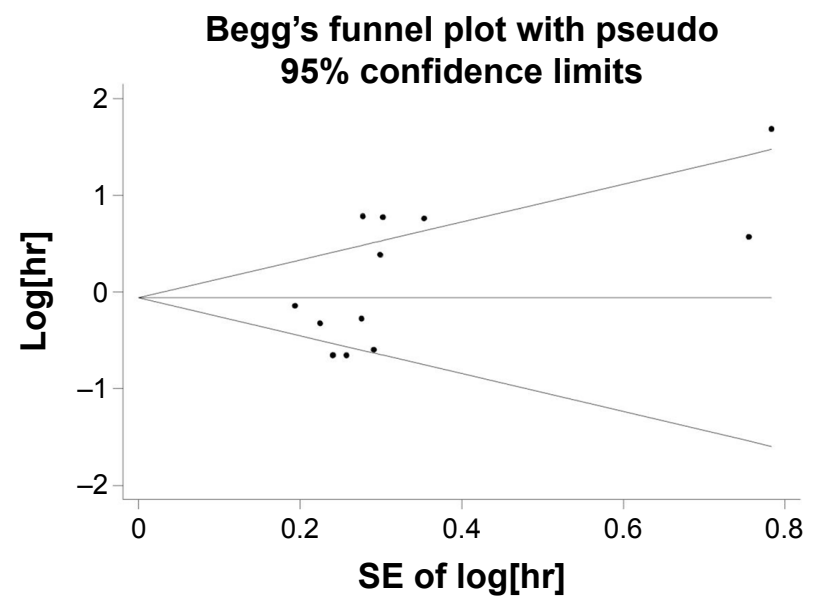

Figure 8 Funnel plot for the evaluation of potential publication bias in the impact of TS expression on overall survival of GC patients in adjuvant setting.

Abbreviations: TS, thymidylate synthase; GC, gastric cancer; SE, standard error; $\mathrm{hr}$, hazard ratio.

\section{Publication bias}

The publication bias was assessed in the association of TS expression and OS in both adjuvant and advanced settings (Figure 8). The results showed that the Egger's tests and Begg's tests were not significant for studies in both settings (adjuvant setting, Egger's test: $P=0.085$, Begg's test: $P=0.115$; advanced setting, Egger's test: $P=0.331$, Begg's test: $P=0.16$ ).

\section{Discussion}

Because of the lack of well-recognized predictive molecular biomarkers for FUC efficacy in GC patients, the hypothesis that TS expression is associated with the chemotherapy response and survival of patients receiving FU-based therapy is an attractive explanation for different patients' outcomes. Thus, we performed this meta-analysis to clarify the precise predictive value of TS expression. Our meta-analysis included 25 studies with 2,442 patients, which analyzed TS expression and clinical outcomes of GC patients who received FUC. Our results suggested that TS expression is significantly correlated with chemotherapy response (OR: 0.43, 95\% CI: $0.22-0.84, P=0.013$ ) and OS (HR: 1.64, 95\% CI: $1.29-2.09, P<0.001)$ or EFS (HR: 1.53 , 95\% CI: $1.21-1.95, P<0.001)$ in the advanced setting.

However, our meta-analysis failed to detect a significant association between TS expression and OS (HR: 1.06, 95\% CI: $0.74-1.50$ ) or EFS (HR: 1.16, 95\% CI: 0.84-1.61) in the adjuvant setting. Considerable heterogeneity was also found in both OS and EFS groups. Meta-regression and subgroup analysis did not ascertain the exact reason for between-group heterogeneity either. But we did observe a decreased trend in heterogeneity of HR for OS among patients with earlier-stage disease, although we were unable to determine a significant correlation between TS expression and survival in patients who received adjuvant chemotherapy (HR: 0.83, 95\% CI: 0.64-1.07). Another important factor that may contribute to heterogeneity is study location or ethnicity; subgroup analysis by region suggested remarkable decreased heterogeneity in Korea, whereas heterogeneity in other regions remained significant. To our knowledge, survival of GC patients who underwent radical surgery is determined by many clinical aspects including patients' other primary diseases, TNM stages, operation approaches, and adjuvant or neoadjuvant chemotherapy regimens. ${ }^{39,40}$ Thus, confounding factors that could not be extracted from the original studies may exacerbate inconsistent results in the adjuvant setting.

Another mechanism may account for chemotherapy efficacy at the transcriptional level. Cui et al discovered a $T S$ gene polymorphism that may portend worse survival in some Chinese patients with advanced GC; ${ }^{41}$ the genotype $3 \mathrm{R} / 3 \mathrm{R}$ (three repeats) in the $T S$ gene promoter might be more likely to cause 5-FU resistance than the $2 \mathrm{R} / 3 \mathrm{R}$ genotype. However, in the meta-analysis of Wang et al, ${ }^{42} 2 \mathrm{R} / 3 \mathrm{R}$ and $2 \mathrm{R} / 2 \mathrm{R}$ in Caucasian colorectal cancer patients treated with 5-FU chemotherapy had worse OS. The results indicated that TS promoter polymorphism might vary with ethnicity and disease type; thus, more studies are required to establish the relationship between $T S$ gene polymorphisms and FUC efficacy accurately.

According to our research, TS expression might be a potential prognostic biomarker for advanced GC patients receiving chemotherapy. Besides the application of wellknown FU-based drugs such as capecitabine and S-1, several new chemotherapeutic drugs were developed. Raltitrexed (Tomudex) is a selective and direct TS inhibitor, which was first applied in colorectal cancer patients. ${ }^{43}$ Recent clinical trial has verified its value in treating GC patients with efficacy and safety. ${ }^{44}$ Therefore, higher TS expression might be regarded as an indicator for the alternative application of Raltitrexed, which still needs more clinical studies to clarify.

Our meta-analysis has several advantages. First, the inclusion and exclusion criteria were rigidly applied to ensure satisfactory quality of the enrolled studies. Second, this is the first such analysis based on studies from both European and Asian countries to our knowledge, which should minimize bias caused by the ethnicity. Third, we explored the TS effect on FUC for both response rate and survival in advanced and adjuvant settings. Fourth, we used meta-regression and subgroup analysis stratified by related factors to identify heterogeneous resource in adjuvant setting. 
The most notable limitation of our study is that exclusion of poor-quality articles (methodological score $<60$ points) may have enforced a selection bias. In addition, the exclusion due to insufficient data for prognosis analysis might also contribute to the selection bias. Another limitation is the approach of extracting and calculating the HRs from studies, which might also be a source of bias, and 14 out of 25 articles were estimated using the methods reported by Parmar et al. ${ }^{10}$ The HRs provided by our extractions might not be as reliable as those calculated by original authors with the raw data. Moreover, the eligible studies comprised two detection methods of TS status, immunohistochemistry and reverse transcriptase polymerase chain reaction (RT-PCR), which may contribute to the heterogeneity between studies. The inconsistent thresholds for TS status determination by both immunohistochemistry and RT-PCR might be another source of bias. For example, most of the RT-PCR subgroup used median value or chi-square value as their cutoffs, except that of Sasako et al ${ }^{8}$ which used the 66.7th percentile as the cutoff point. A significant impact was also found in the association between TS expression and OS (HR: $0.370,95 \%$ CI: $0.221-0.619)$ but became insignificant (HR: $0.995,95 \%$ CI: 0.766-1.293) when the cutoff was changed to the $33.3 \mathrm{rd}$ percentile, which demonstrated a vulnerable effect of survival data according to cutoff points. As we only enrolled studies fully published in English, unpublished studies and conference abstracts were excluded, as well as publications in other languages. Therefore, although the Begg's tests and Egger's tests did not find significant publication bias for analysis of association between TS expression and OS, publication bias may still exist in our study to some extent. It is also one of our study's limitations that we did not have enough information for comparing the prognostic value of GC patients with chemotherapy versus those without, which would affect the precision of our finding.

In conclusion, our study indicates that TS expression can predict both drug efficacy and survival of advanced GC patients treated with FUC. However, more multicentered prospective studies with consistent and standardized methodology are needed to further confirm and strengthen our findings.

\section{Acknowledgments}

This study was funded by the National Nature Science Foundation of China (No 81272698) and a grant from PLA Medical Technology key project of scientific research in the 12th Five Year Plan (No BWS12J049).

\section{Disclosure}

The authors report no conflicts of interest in this work.

\section{References}

1. Stewart BW, Wild CP, editors. World Cancer Report 2014. Lyon, France: International Agency for Research on Cancer; 2014.

2. Hayward JL, Rubens RD, Carbone PP, Heuson JC, Kumaoka S, Segaloff A. Assessment of response to therapy in advanced breast cancer. A project of the programme on clinical oncology of the International Union against Cancer, Geneva, Switzerland. Eur J Cancer. 1978;14(11):1291-1292.

3. Buscariollo DL, Mamon HJ. Optimal management of resectable gastric adenocarcinoma. Expert Rev Anticancer Ther. 2015;15(8): 931-941.

4. Marin JJ, Al-Abdulla R, Lozano E, et al. Mechanisms of resistance to chemotherapy in gastric cancer. Anticancer Agents Med Chem. Epub 2015 August 3.

5. Sharp L, Little J. Polymorphisms in genes involved in folate metabolism and colorectal neoplasia: a HuGE review. Am J Epidemiol. 2004; 159(5):423-443.

6. Longley DB, Harkin DP, Johnston PG. 5-Fluorouracil: mechanisms of action and clinical strategies. Nat Rev Cancer. 2003;3(5):330-338.

7. Yeh CN, Jung SM, Chen TW, Hwang TL, Jan YY, Chen MF. Expression of thymidylate synthase determines the response of gastric cancer patients undergoing gastrectomy to 5-fluorouracil-based adjuvant chemotherapy. Langenbecks Arch Surg. 2010;395(3):217-225.

8. Sasako M, Terashima M, Ichikawa W, et al. Impact of the expression of thymidylate synthase and dihydropyrimidine dehydrogenase genes on survival in stage II/III gastric cancer. Gastric Cancer. 2015; 18(3):538-548.

9. Hu HB, Kuang L, Zeng XM, Li B, Liu EY, Zhong MZ. Predictive value of thymidylate synthase expression in gastric cancer: a systematic review with meta-analysis. Asian Pac J Cancer Prev. 2012;13(1): 261-267.

10. Parmar MK, Torri V, Stewart L. Extracting summary statistics to perform meta-analyses of the published literature for survival endpoints. Stat Med. 1998;17(24):2815-2834.

11. Tierney JF, Stewart LA, Ghersi D, Burdett S, Sydes MR. Practical methods for incorporating summary time-to-event data into meta-analysis. Trials. 2007;8:16.

12. Stang A. Critical evaluation of the Newcastle-Ottawa scale for the assessment of the quality of nonrandomized studies in meta-analyses. Eur J Epidemiol. 2010;25(9):603-605.

13. Steels E, Paesmans M, Berghmans T, et al. Role of $\mathrm{p} 53$ as a prognostic factor for survival in lung cancer: a systematic review of the literature with a meta-analysis. Eur Respir J. 2001;18(4):705-719.

14. Altman DG. Systematic reviews of evaluations of prognostic variables. BMJ. 2001;323(7306):224-228.

15. Kwon HC, Roh MS, Oh SY, et al. Prognostic value of expression of ERCC1, thymidylate synthase, and glutathione S-transferase P1 for 5-fluorouracil/oxaliplatin chemotherapy in advanced gastric cancer. Ann Oncol. 2007;18(3):504-509.

16. Kim KH, Kwon HC, Oh SY, et al. Clinicopathologic significance of ERCC1, thymidylate synthase and glutathione S-transferase P1 expression for advanced gastric cancer patients receiving adjuvant 5-FU and cisplatin chemotherapy. Biomarkers. 2011;16(1):74-82.

17. Van Hoe L, Van Cutsem E, Vergote I, Marchal G, Baert AL. Reporting on the results of cancer treatment in patients with metastatic liver disease: proposal of symmetric size-dependent CT-criteria for response. Ann Oncol. 1996;7(8):871-872.

18. Choi JH, Lim HY, Joo HJ, et al. Expression of multidrug resistanceassociated protein1, P-glycoprotein, and thymidylate synthase in gastric cancer patients treated with 5-fluorouracil and doxorubicin-based adjuvant chemotherapy after curative resection. Br J Cancer. 2002;86(10): $1578-1585$. 
19. Grau JJ, Domingo-Domenech J, Morente V, et al. Low thymidylate synthase expression in the primary tumor predicts favorable clinical outcome in resected gastric cancer patients treated with adjuvant tegafur. Oncology. 2004;66(3):226-233.

20. Lee J, Park CK, Park JO, et al. Impact of E2F-1 expression on clinical outcome of gastric adenocarcinoma patients with adjuvant chemoradiation therapy. Clin Cancer Res. 2008;14(1):82-88.

21. Kim JS, Kim MA, Kim TM, et al. Biomarker analysis in stage III-IV (M0) gastric cancer patients who received curative surgery followed by adjuvant 5-fluorouracil and cisplatin chemotherapy: epidermal growth factor receptor (EGFR) associated with favourable survival. Br J Cancer. 2009;100(5):732-738.

22. Ishido K, Azuma M, Koizumi W, et al. Evaluation of prognostic factors for the response to S-1 in patients with stage II or III advanced gastric cancer who underwent gastrectomy. Pharmacogenet Genomics. 2009;19(12):955-964

23. Jeong $\mathrm{SH}$, Han JH, Kim JH, et al. Bax predicts outcome in gastric cancer patients treated with 5-fluorouracil, leucovorin, and oxaliplatin palliative chemotherapy. Dig Dis Sci. 2011;56(1):131-138.

24. De Dosso S, Zanellato E, Nucifora M, et al. ERCC1 predicts outcome in patients with gastric cancer treated with adjuvant cisplatin-based chemotherapy. Cancer Chemother Pharmacol. 2013;72(1):159-165.

25. Yeh KH, Shun CT, Chen CL, et al. High expression of thymidylate synthase is associated with the drug resistance of gastric carcinoma to high dose 5-fluorouracil-based systemic chemotherapy. Cancer. 1998;82(9): 1626-1631.

26. Suda Y, Kuwashima Y, Tanaka Y, et al. Expression of thymidylate synthase and thymidine phosphorylase in recurrence and survival rates of advanced gastric cancer. Gastric Cancer. 1999;2(3):165-172.

27. Miyamoto S, Boku N, Ohtsu A, et al. Clinical implications of immunoreactivity of thymidylate synthase and dihydropyrimidine dehydrogenase in gastric cancer treated with oral fluoropyrimidine (S-1). Study Group of S-1 for Gastric Cancer. Int J Oncol. 2000;17(4):653-658.

28. Ichikawa W, Takahashi T, Suto K, et al. Thymidylate synthase predictive power is overcome by irinotecan combination therapy with S-1 for gastric cancer. Br J Cancer. 2004;91(7):1245-1250.

29. Cho MY, Yi SY, Eom M, et al. A high thymidylate synthase expression is related to better outcome for advanced gastric cancer patients treated with 5-FU chemotherapy after curative resection. Korean J Pathol. 2006;40(2):128-136.

30. Hua D, Huang ZH, Mao Y, Deng JZ. Thymidylate synthase and thymidine phosphorylase gene expression as predictive parameters for the efficacy of 5-fluorouracil-based adjuvant chemotherapy for gastric cancer. World J Gastroenterol. 2007;13(37):5030-5034.

31. Matsubara J, Nishina T, Yamada Y, et al. Impacts of excision repair cross-complementing gene 1 (ERCC1), dihydropyrimidine dehydrogenase, and epidermal growth factor receptor on the outcomes of patients with advanced gastric cancer. Br J Cancer. 2008;98(4):832-839.
32. Akamoto S, Usuki H, Haba R, et al. The discrepancy in thymidylate synthase and dihydropyrimidine dehydrogenase expression depending on measurement methodologies in stage 4 gastric cancer. Hepatogastroenterology. 2008;55(86-87):1882-1886.

33. Wei J, Zou Z, Qian X, et al. ERCC1 mRNA levels and survival of advanced gastric cancer patients treated with a modified FOLFOX regimen. Br J Cancer. 2008;98(8):1398-1402.

34. Koizumi W, Tanabe S, Azuma M, et al. Impacts of fluorouracilmetabolizing enzymes on the outcomes of patients treated with S-1 alone or S-1 plus cisplatin for first-line treatment of advanced gastric cancer. Int J Cancer. 2010;126(1):162-170.

35. Choi IS, Lee HS, Lee KW, et al. Biomarker analysis in patients with advanced gastric cancer treated with S-1 plus cisplatin chemotherapy: orotate phosphoribosyltransferase expression is associated with treatment outcomes. Med Oncol. 2011;28(4):991-998.

36. Jeung HC, Rha SY, Shin SJ, et al. Predictive values of 5-fluorouracil pathway genes for S-1 treatment in patients with advanced gastric cancer. Anticancer Drugs. 2011;22(8):801-810.

37. Lu M, Gao J, Wang XC, Shen L. Expressions of thymidylate synthase, thymidine phosphorylase, class III beta-tubulin, and excision repair cross-complementing group 1 predict response in advanced gastric cancer patients receiving capecitabine plus paclitaxel or cisplatin. Chin J Cancer Res. 2011;23(4):288-294.

38. Liu XF, Zhang H, Sun JQ, et al. Correlation between expression of thymidylate synthase and clinical outcome of advanced gastric cancer treated with capecitabine alone chemotherapy. Tumour Biol. 2014;35(12): 12409-12414

39. Wolfson JA, Sun CL, Wyatt LP, Hurria A, Bhatia S. Impact of care at comprehensive cancer centers on outcome: results from a populationbased study. Cancer. 2015;121(21):3885-3893.

40. Schlesinger-Raab A, Mihaljevic AL, Egert S, et al. Outcome of gastric cancer in the elderly: a population-based evaluation of the Munich Cancer Registry. Gastric Cancer. Epub 2015 August 11.

41. Cui YH, Liu TS, Zhuang RY, Gao HJ, Li H. Polymorphism of thymidylate synthase gene and chemosensitivity of 5-fluorouracil regimen in metastatic gastrointestinal cancer. J Dig Dis. 2009;10(2):118-123.

42. Wang YC, Xue HP, Wang ZH, Fang JY. An integrated analysis of the association between Ts gene polymorphisms and clinical outcome in gastric and colorectal cancer patients treated with 5-FU-based regimens. Mol Biol Rep. 2013;40(7):4637-4644.

43. Cunningham D, Zalcberg J, Maroun J, et al. Efficacy, tolerability and management of raltitrexed (Tomudex) monotherapy in patients with advanced colorectal cancer: a review of phase II/III trials. Eur J Cancer. 2002;38(4):478-486.

44. Zhao P, Ding Z, Tang L, Zhou X. Preliminary investigation of intraperitoneal raltitrexed in patients with gastric cancer. World J Surg Oncol. 2014; $12: 403$
OncoTargets and Therapy

\section{Publish your work in this journal}

OncoTargets and Therapy is an international, peer-reviewed, open access journal focusing on the pathological basis of all cancers, potential targets for therapy and treatment protocols employed to improve the management of cancer patients. The journal also focuses on the impact of management programs and new therapeutic agents and protocols on
Dovepress

patient perspectives such as quality of life, adherence and satisfaction The manuscript management system is completely online and includes a very quick and fair peer-review system, which is all easy to use. Visit http://www.dovepress.com/testimonials.php to read real quotes from published authors. 